\section{Denture Tumor: The Uninvited Distress amongst the Geriat- rics - A Case Report}

Keywords: Dentures; Gingival Diseases; Mucous membrane; Neoplasms; Geriatrics

\begin{abstract}
Dentures are prosthetic devices constructed to aid as a replacement for the missing teeth. However, the problems come when there is no right fitting as it can turn into a potpourri of problems for the patient. Discomfort in mastication, speech, pain and inflammation are just some of the ill-effects of an ill-fitting denture. Epulis fissuratum refers to reactive tissue response to excessive mechanical pressure imparted by the poor fit of prosthesis. In this article, we discuss one such case of a 63-year-old female.
\end{abstract}

\section{Introduction}

Epulis Fissuratum (EF), a benign tumor like inflammatory hyperplastic growth occurs on the mucosa along the borders of an ill-fitting full or partial removable denture [1]. It usually results from chronic low-grade trauma induced by a denture flange [2]. Clinically, EF appears as a single or multiple folds of hyperplastic tissue along the borders of the denture [3]. Hereby, we present a case of 63-yearold female with EF on the anterior maxillary alveolar ridge.

\section{Case Report}

A 63-year-old medically fit female visited our department with a chief complaint of an abnormal growth underneath the anterior portion of her ill-fitting maxillary complete denture. She had first noticed a small swelling about 6 months back, which gradually grew in size overtime. The particular denture had been fabricated about 2 years ago. The patient had been suffering from pain and discomfort during mastication for the past 3 months. Meanwhile, she also gave a history of wearing the denture during night time.

Systemic examination revealed no significant abnormality. On intraoral examination, the salient points noted were-partially edentulous mandibular arch with multiple grossly decayed teeth and root stumps (Figure 1A). Anterior portion of the maxillary arch revealed two sessile fibrous tissue folds extending on either side of the midline, predominantly on the right side. Growth was seen on either side of the vestibule, along the labial mucosa and the labial surface of the alveolar mucosa which had multiple, ovoid and nodular overgrowths with overlying and surrounding erythema. The lesion was polypoid, soft in consistency, and smooth in texture (Figure 1B).

According to the patient's history and clinical examination, a provisional diagnosis of EF was established. As patient was not in favour of any surgical intervention, patient was advised to discontinue wearing the ill-fitting prosthesis. Successive follow-ups were done at an interval of 1 week, 4 weeks and 8 weeks which showed regression in size of growth. After 3 months, complete regression was noted and a removable complete denture was fabricated.

\section{Journal of}

Clinical \& Medical Case Reports

\section{Kamakshi, Geon Pauly N*, Prasanna Kumar Rao, Roopashri Rajesh Kashyap, Gowri P Bhandarkar and Raghavendra Kini}

Department of Oral Medicine and Radiology, A J Institute of Dental Sciences, India

Address for Correspondence:

Geon Pauly N, Department of Oral Medicine and Radiology, A J Institute of Dental Sciences, Kuntikana, Mangaluru, Karnataka-575004, India, Tel: +918905102696; E-mail: geonpauly@gmail.com

Submission: 13 February, 2018

Accepted: 30 March, 2018

Published: 05 April, 2018

Copyright: (c) 2018 Kamakshi, et al. This is an open access article distributed under the Creative Commons Attribution License, which permits unrestricted use, distribution, and reproduction in any medium, provided the original work is properly cited.

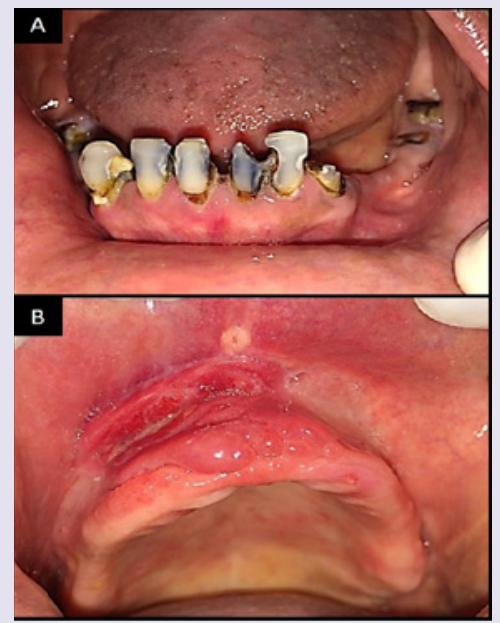

Figure 1: A) Partially edentulous mandibular arch with grossly decayed teeth and root stumps. B) Epulis fissuratum in relation to the maxillary anterior labial and alveolar mucosa.

\section{Discussion}

The term 'epulis' was coined by Virchoff, and its dictionary meaning is 'over the gums' [4]. 'Epulis fissuratum' also known as 'Granuloma fissuratum' is an oral pathologic condition that appears in the oral cavity as an overgrowth of fibrous connective tissue. It is also known as inflammatory fibrous hyperplasia, denture epulis, denture induced fibrous hyperplasia [5].

Trauma and irritation are the two main aetiological factors responsible for occurrence of epulis. Clinically, it presents as a raised sessile lesion in the form of folds with a smooth surface with normal or erythematous overlying mucosa as seen in our case. Because of chronic irritation, it may get traumatised and present with an ulcerated surface [6]. It not only produces pain and discomfort but negatively affects the mastication, aesthetics and overall well-being of the patient. Chronic trauma to oral mucosa may predispose the patient to carcinoma [7]. 
Citation: Kamakshi, Geon Pauly N, Rao PK, Kashyap RR, Bhandarkar GP, et al. Denture Tumor: The Uninvited Distress amongst the Geriatrics - A Case Report. J Clin Med Case Reports. 2018;5(1): 2.

ISSN: $2332-4120$

EF can be treated surgically or conservatively. In the early stage, denture coverage with a soft liner material is frequently sufficient for elimination or reduction of the lesion. However, in later stages, when the hyperplastic tissue is composed of significant fibrosis, surgical excision is the treatment of choice [8]. Surgical options include scalpel biopsy or carbon dioxide laser excision. This is followed by fabrication of a new set of adequately fitting dentures [9]. In a recent case report, the use of liquid nitrogen cryosurgery has been suggested to manage epulis fissuratum in geriatric patients [8].

\section{Conclusion}

The complete removable denture plays an important role in improving the quality of life of edentulous patient. But if the denture is poorly adapted then the plethora of problems only multiplies. This can be avoided by establishing appropriate hygiene means and periodic checks of dentures to prevent bone resorption and in turn possibilities of fibrous hyperplasia. For as the good old saying goes "A stitch in time, can certainly save nine".

\section{References}

1. Kumar AM, Veena KM, Chatra L, Shenai P, Rao PK, et al. (2014) Denture induced inflammatory hyperplasia-A case report. Pac J Med Sci 13: 31-35.
2. Kalavathy N, Sridevi J, Kumar PR, Sharmila MR, Jayanthi N (2010) Denture induced fibrous hyperplasia: A Case Report. SRM J Res Dent Sci 1: 305-307.

3. Monteiro LS, Mouzinho J, Azevedo A, Camara MI, Martins MA, et al. (2012) Treatment of epulis fissuratum with carbon dioxide laser in a patient with antithrombotic medication. Braz Dent J 23: 77-81.

4. Tamarit-Borras M, Delgado-Molina E, Berini-Aytes L, Gay-Escoda C (2005) Removal of hyperplastic lesions of the oral cavity. A retrospective study of 128 cases. Med Oral Patol Oral Cir Bucal 10: 151-162.

5. Patil BA, Arora A, Sodhi A (2014) Report of a case of epulis fissuratum. Sch J Med Case Rep 2: 452-454.

6. Mohan RP, Verma S, Singh U, Agarwal N (2013) Epulis fissuratum: Consequence of ill-fitting prosthesis. BMJ Case Rep 2013.

7. Niccoli-Filho W, Neves AC, Penna LA, Seraidarian PI, Riva R (1999) Removal of epulis fissuratum associated to vestibuloplasty with carbondioxide laser. Lasers Med Sci 14: 203-206.

8. Mortazavi H, Khalighi HR, Jafari S, Baharvand M (2016) Epulis fissuratum in the soft palate: Report of a case in a very rare location. Dent Hypotheses 7: 67-69.

9. Thomas GA (1993) Denture-induced fibrous inflammatory hyperplasia (epulis fissuratum): Research aspects. Aus Prosthodont J 7: 49-53. 